\title{
Effects of surgical ventricular reconstruction on diastolic function at midterm follow-up
}

\author{
Marisa Di Donato, MD, ${ }^{\mathrm{a}, \mathrm{b}}$ Lorenzo Menicanti, MD, ${ }^{\mathrm{a}}$ Marco Ranucci, MD, ${ }^{\mathrm{c}}$ Serenella Castelvecchio, MD, ${ }^{\mathrm{a}}$ \\ Carlo de Vincentiis, MD, ${ }^{\mathrm{a}}$ Josephal Salvia, MD, ${ }^{\mathrm{a}}$ and Tammam Yussuf, $\mathrm{MD}^{\mathrm{a}}$
}

\begin{abstract}
Objective: Limited data are available on the effects of surgical ventricular reconstruction on diastolic function. The aim of the present study was to evaluate changes in diastolic function induced by surgical ventricular reconstruction at 2 time intervals after surgery (discharge and follow-up) and to assess the impact of diastolic changes on clinical outcome.
\end{abstract}

Methods: A total of 129 patients ( $65 \pm 9$ years, 14 women) underwent echocardiographic Doppler evaluation before surgical ventricular reconstruction, at discharge, and at follow-up (median 7 months). Patients with mitral regurgitation were excluded. Diastolic pattern was graded as follows: 0 (normal), 1 (abnormal relaxation), 2 (pseudo normalization), 3 (restrictive, reversible), and 4 (restrictive, irreversible).

Results: At follow-up, 28 (21.7\%) of 129 patients showed a restrictive diastolic pattern (grade 3-4; group 1) and 101 did not (diastolic pattern grade $0-2$; group 2). Preoperative and postoperative factors strongly associated with late diastolic restriction included sphericity index (higher in group 1), ventricular shape (nonaneurysmal shape more frequent in group 1), internal dimensions (greater in group 1), diastolic pattern (higher in group 1), ejection fraction (lower in group 1); left atrial dimensions (greater in group 1); mitral regurgitation rate (higher in group 1). At multivariate analysis the most powerful predictors of restriction were preoperative pseudonormalization of diastolic pattern (diastolic pattern 2) and septolateral dimensions (short axis). Overall, ejection fraction improved from $33 \% \pm 9 \%$ to $40 \% \pm 9 \%$ to $40 \% \pm 9 \% ; P=.001$; end-diastolic and end-systolic volumes decreased (112 \pm 41 to $73 \pm 21$ to $88 \pm 28 \mathrm{~mL} / \mathrm{m}^{2}$, respectively; $P=.001$; and $77 \pm 38$ to $44 \pm 17$ to $52 \pm 24 \mathrm{~mL} / \mathrm{m}^{2}$, respectively; $P=.001)$; New York Heart Association class improved ( $2.4 \pm 0.8$ to $1.6 \pm 0.6 ; P=.001)$.

Conclusions: Mild preoperative diastolic dysfunction (pseudonormalized pattern) and increased septolateral dimensions are independent predictors of diastolic restriction after surgical ventricular reconstruction. (J Thorac Cardiovasc Surg 2010;140:285-91)

Supplemental material is available online.

Surgical ventricular reconstruction (SVR) is an effective treatment option for dilated ischemic cardiomyopathy. ${ }^{1}$ It has been consistently demonstrated that SVR improves cardiac systolic function, clinical status, and survival, ${ }^{1-7}$ but only a few studies describe the effects of SVR on diastolic performance and are mainly addressing the acute, postoperative effects.

Experimental data and theoretical considerations suggest an impairment of diastolic function after SVR. ${ }^{8-10}$ Besides

\footnotetext{
From the Department of Cardiac Surgery, ${ }^{\text {a }}$ IRCCS San Donato Hospital, Milan, Italy; the Department of Critical Care Medicine, ${ }^{\mathrm{b}}$ University of Florence, Florence, Italy; and the Department of Cardiothoracic-vascular Anaesthesia and ICU, ${ }^{\mathrm{c}}$ IRCCS San Donato Hospital, Milan, Italy.

Disclosures: None.

Received for publication June 12, 2009 ; revisions received Sept 15, 2009; accepted for publication Oct 22, 2009; available ahead of print Dec 28, 2009.

Address for reprints: Marisa Di Donato, MD, Department of Cardiac Surgery, Policlinico San Donato, IRCCS, Via Morandi 30, 20097 San Donato Milanese, Milano, Italy (E-mail: marad@tin.it).

0022-5223/\$36.00

Copyright (C) 2010 by The American Association for Thoracic Surgery

doi:10.1016/j.jtcvs.2009.10.027
}

the intrinsic elastic properties of the nonexcluded myocardial wall, the factor most likely to affect diastolic function is the size of the residual left ventricular (LV) cavity, and surgeons worry about leaving too small a cavity. The use of a sizing device during $\mathrm{LV}$ reconstruction was in fact introduced to reduce such a risk.

The gold standard for diastolic function evaluation and filling pressures is its direct measurement during catheterization. Unfortunately, this invasive method is hardly suitable for widespread use and routine follow-up. The study from Tulner and colleagues, ${ }^{11}$ using pressure/volume curves to evaluate diastolic function, showed a leftward shift of the end-systolic and end-diastolic pressure/volume relation with an increased slope of both, suggesting an improvement in systolic function and counteracting changes in diastolic properties, as evidenced by an increased stiffness constant. However, the study was conducted under cardioplegia, which could be partially responsible for interstitial edema and increased diastolic chamber stiffness.

Conventional Doppler echocardiography can assess LV diastolic function by using transmitral flow velocity profiles and allows complete examination to be repeated after surgery. The diastolic function parameters derived by 


\section{Abbreviations and Acronyms \\ $\mathrm{DP}=$ diastolic pattern \\ $\mathrm{LV}=$ left ventricular \\ MI = myocardial infarction \\ $\mathrm{MR}=$ mitral regurgitation \\ $\mathrm{SVR}=$ surgical ventricular reconstruction}

transmitral flow pattern are, however, dependent on various factors, for example, heart rate and loading conditions.

The aim of the present study was to evaluate midterm changes in diastolic performance, as evaluated by transmitral flow velocity pattern, in patients submitted to SVR and to assess the impact on clinical outcome.

\section{PATIENTS AND METHODS \\ Patients}

In our institution, SVR is a standard of care procedure after infarction for patients with LV dilatation, depressed pump function, and symptoms of angina, heart failure, or a combination of the two. The criteria for performing this procedure have been reported. ${ }^{4,5}$

For the purpose of this study, we analyzed patients without significant mitral regurgitation (MR; grade $\geq 3+$ were excluded) submitted to SVR who survived the operation and who had a complete echocardiographic examination at 3 time intervals: preoperatively, at discharge, and at follow-up. A total of 129 patients met these criteria and represent the study group. We excluded patients with MR because MR affects the transmitral flow velocity curves. A total of 119 patients had anterior myocardial infarction (MI), 4 had double-site MI (anterior and inferior), and 6 had posteroinferior MI. At the time of surgery, all patients were receiving optimal medical therapy.

\section{Data Collection}

Demographic, clinical, echocardiographic, operative, medications, and follow-up data of patients submitted to SVR are derived from our prospectively collected database, which was approved by our institutional ethical committee. Follow-up data assessing clinical status, mortality, and cardiac events are collected by telephone interview or in our outpatient clinic. Recording of events includes cardiac-related hospitalization rate, medications, cardiac procedure rate (such as percutaneous transluminal coronary angioplasty), cardiac pacing, defibrillator/biventricular pacing implantation, and reintervention.

\section{Echocardiography}

Complete M-mode and 2-dimensional echocardiography and Doppler ultrasound assessment were performed using a commercial imaging system (Vivid 7; GE Medical Systems, Waukesha, Wis) before SVR, at the time of discharge (1 week to 10 days after the operation), and at follow-up. Hemodynamic and geometric parameters were collected in all patients at the 3 time intervals. Sphericity index (short axis/long axis ratio) and conicity index (apical/short axis ratio) were calculated at the 3 time intervals to allow a distinction between true aneurysm (type 1) and nonaneurysmal dilated ischemic cardiomyopathy (types 2 and 3$)^{12}$ and to assess changes in LV shape. Diastolic performance was explored by the transmitral flow velocity curve obtained by pulsed Doppler imaging, positioning the sample volume between the tips of the mitral leaflets. According to the transmitral flow velocity pattern, diastolic function was described as normal (diastolic pattern [DP] 0), abnormal relaxation (DP 1) pseudonormal (DP 2), reversible restrictive (DP 3), and irreversible restrictive (DP 4) ${ }^{13}$ (Figure 1). A mean of 3 consecutive cycles was used for the calculations of all echo-Doppler parameters. Echocardiography was always performed by the same cardiologist with great experience in evaluating patients referred for SVR, and measures were made in triplicate with the patient in sinus rhythm.

\section{Surgical Technique}

Details of the surgical technique have been previously reported. ${ }^{4,5,14,15}$ The procedure is conducted on an arrested heart with antegrade blood cold cardioplegia. Complete coronary revascularization is first performed, almost always with the left internal thoracic artery grafted onto the left anterior descending coronary artery, and sequential venous grafts onto the right and circumflex arteries are performed if needed. Then the ventricle is opened on the anterior wall with an excision parallel to the left anterior descending; the cavity is carefully checked and thrombi are removed if present. The reconstruction of the ventricle is accomplished with the Mannequin (TRISVR System, Chase Medical, Richardson, Tex) filled at 50 to $60 \mathrm{~mL} /$ $\mathrm{m}^{2}$ to optimize the size and the shape of the new ventricle. An endoventricular circular suture is conducted at the transitional zone, starting at the level of the new apex identified by the Mannequin, going deep into the septum and high toward the aorta following an oblique plane. The suture then goes toward the lateral wall, back to the apex, and is tightened over the device that is removed at the completion of the SVR. The ventricle is closed with a Dacron patch if the ventricular opening is greater than $3 \mathrm{~cm}$ or with a direct suture if it is less than $3 \mathrm{~cm}$. The excluded tissue is closed over the patch.

\section{Statistical Analysis}

Statistical analysis included the analysis of variance with Bonferroni within-group comparison, independent variables Student $t$ test for comparison between 2 groups (continuous variables), or Pearson's $\chi^{2}$ (categorical variables).

The univariate association of potential risk factors (preoperative and operation-related) with the presence of diastolic function restrictive pattern at follow-up was explored with a logistic regression analysis for continuous variables and a Pearson $\chi^{2}$ with relative risk analysis for categorical variables. The multivariable risk analysis was based on a multivariate stepwise forward logistic regression analysis. Adequate cutoff points were tested with a receiver operating characteristic analysis, with assessment of the area under the curve and relative $95 \%$ standard error.

Survival was explored with Kaplan-Meier actuarial curves .

Values are expressed as mean \pm standard deviation or as number and percentage.

Statistical calculations were performed with a computerized statistical program (SPSS 11.0; SPSS, Inc, Chicago, Ill).

\section{RESULTS \\ Patient Characteristics}

The preoperative clinical characteristics of the study group are reported in Table 1. All patients had SVR; 123 (95\%) patients had concomitant coronary artery bypass; an endoventricular patch was used in 64 patients $(50 \%)$; the mean number of anastomosis was $2.8 \pm 1.3$.

\section{Diastolic Performance}

At baseline, diastolic function was normal in 4 patients; 84 patients had abnormal relaxation pattern, pseudonormalization was present in 34 , and a restrictive pattern was present in 7 patients (1 irreversible). Preoperatively, patients with mild to severe diastolic dysfunction (DP $\geq 2$ ) show significant differences in LV shape and LV function compared 


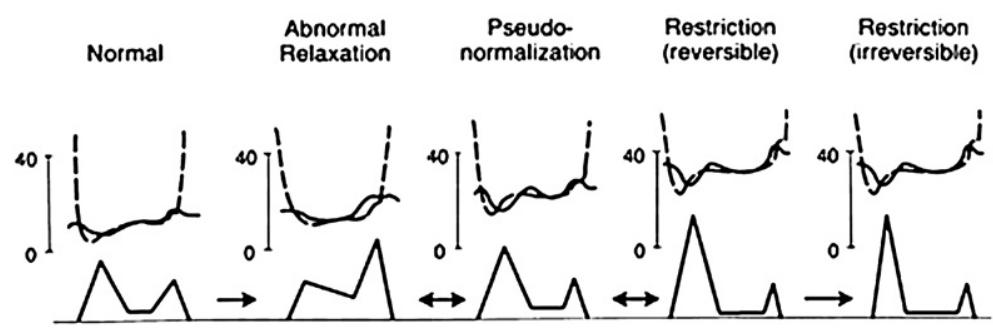

\section{Diastolic pattern}

FIGURE 1. Grade of diastolic dysfunction named diastolic pattern as evaluated by transmitral flow velocity curves. Comparison with hemodynamic left ventricular filling pressure at different stages of diastolic dysfunction. Modified from Nishimura R, Tajic JA. Evaluation of diastolic filling of left ventricle in health and disease: Doppler echocardiography is the clinician's Rosetta Stone. J Am Coll Cardiol. 1997;30:8-18.

with patients with normal or slightly abnormal diastolic function: end-diastolic and end-systolic volume indexes are larger $\left(130 \pm 62\right.$ and $94 \pm 57 \mathrm{~mL} / \mathrm{m}^{2}$ vs $102 \pm 29$ and $67 \pm 26 \mathrm{~mL} / \mathrm{m}^{2}$, respectively; $\left.P=.001\right)$; ejection fraction is lower $(30 \% \pm 9 \%$ vs $35 \% \pm 8 \% ; P=.005)$, sphericity index is higher $(0.57 \pm 0.11$ vs $0.51 \pm 0.08$ in diastole; $P=$ $.008 ; 0.50 \pm 0.15$ vs $0.42 \pm 0.09$ in systole; $P=.002$ ), left atrial size is larger ( $47 \pm 6 \mathrm{vs} 42 \pm 7 \mathrm{~mm} ; P=.000$ ), and so is mitral annulus size ( $34 \pm 4$ vs $31 \pm 5 \mathrm{~mm}$; $P=.000$ ). Although not significant, conicity index is lower in systole $(0.95 \pm 0.19$ vs $1.0 \pm 0.27)$, indicating a more conical apex.

Postoperative echocardiographic data early after surgery and at follow-up (median time from surgery $=7$ months) showed an average worsening of DP (DP from $1.37 \pm 0.7$ to $1.46 \pm 0.7$ to $1.67 \pm 1.01 ; P=.02)$ and of deceleration time (from $206 \pm 58$ to $175 \pm 50 \mathrm{~ms} ; P=.002$ ), with deceleration time increase at follow-up to $194 \pm 57 \mathrm{~ms}$ (no longer significant in respect to basal). Five of the 7 patients with baseline restrictive pattern improved at follow-up to abnormal relaxation (3 patients), to pseudonormal pattern (1 patient), and to normal diastolic function (1 patient). Two patients remained with a restrictive pattern and 26 developed restriction, accounting for a total of $28(21.7 \%)$ patients with severe diastolic dysfunction ( $\geq$ grade 3 ); 8 of 28 patients showed an irreversible restrictive pattern (DP 4) (Figure 2).

Patients were then divided into 2 groups: group 1 with diastolic restriction (DP 3-4) at follow-up $(\mathrm{n}=28)$ and group 2 without restriction $(n=101)$. Table 2 shows preoperative and postoperative echocardiographic parameters in the 2 groups. Group 1 patients were younger than group 2. Preoperatively, LV internal dimensions were greater and ejection fraction was lower, whereas LV volumes, although larger in group 1 , were not significantly different. Left atrial size was greater; short axis (septolateral dimension, obtained in apical 4-chamber view) was greater both in diastole and in systole, and sphericity index was higher (more spherical chamber), whereas conicity index in systole was lower (more conical apex). Preoperative nonaneurysmal LV shape, defined as type 2 and type 3 according to the Di Donato classification, ${ }^{12}$ was more frequent in patients in whom diastolic restriction developed (64\%); none of the patients with classic true aneurysm (type 1) had diastolic restriction, nor did they show restriction at baseline; Diabetes and multivessel disease were more frequent in group $1(P=.033$ and .024 , respectively).

Analyzing early postoperative data as function of late restriction, univariate analysis still shows $\mathrm{LV}$ postoperative internal diameters, left atrial size, short axis, sphericity index and DP (DP 2) significantly associated with late restriction (Table 2). Postoperative LV volumes are significantly larger in patients with restriction, and significant late MR (grade

TABLE 1. Clinical characteristics $(n=129)$

\begin{tabular}{lcc}
\hline & No. & $(\%)$ \\
\hline Age (y) & $65 \pm 9$ & \\
Male/female & $115 / 14$ & \\
Diabetes type 1 & 3 & $(2.3)$ \\
Diabetes type 2 & 28 & $(22)$ \\
Hypertension & 69 & $(53)$ \\
Impaired renal function* & 7 & $(5.4)$ \\
Atrial fibrillation & 14 & $(11)$ \\
Previous stroke & 11 & $(8.5)$ \\
Angina & 65 & $(50)$ \\
Unstable & 13 & $(10)$ \\
Multivessel disease & 84 & $(65)$ \\
NYHA III-IV & 51 & $(40)$ \\
Current medications & & \\
ACE inhibitors & 108 & $(85)$ \\
Beta-blockers & 84 & $(65)$ \\
Aspirin & 87 & $(67)$ \\
Diuretics & 90 & $(70)$ \\
Nitrates & 52 & $(40)$ \\
Statins & 65 & $(50)$ \\
Digoxin & 8 & $(6.2)$ \\
\hline NYHA, New York & & \\
\hline
\end{tabular}

NYHA, New York Heart Association; $A C E$, angiotensin-converting enzyme. *Defined as creatinine level greater than 1.5 . 


\section{Diastolic Pattern changes following SVR (pre-op to follow-up)}

DP Grade

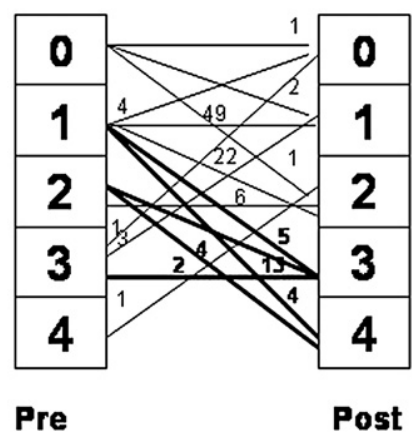

FIGURE 2. Line plots demonstrating changes from preoperative performance to follow-up. Thicker lines refer to 28 patients showing diastolic restriction (grade 3-4) at follow-up. DP, Diastolic pattern.

$3+)$ is more frequent $\left(5 / 28 ; P=.001\right.$ at $\chi^{2}$ test). Figure E1 shows the average DP in the 2 groups at the 3 intervals; note the highest preoperative value in patients who have late restriction and the significant increase at discharge and follow-up.

At multivariate analysis (stepwise forward logistic regression analysis), 2 preoperative factors resulted in independent predictors of late diastolic restrictive pattern: pseudonormalized DP, that is, DP 2 (relative risk, 7.6; 95\% confidence interval, 2.3-25), and short axis in systole, (relative risk: 8.06; confidence interval $1.7-37.8 ; P=.008$ ). A preoperative short-axis value of $4.2 \mathrm{~cm}$ resulted in the value with the highest sensitivity $(78 \%)$ and specificity $(60 \%)$ at the receiver operating characteristic analysis. The area under the curve was 0.793 (95\% confidence interval, 0.65-0.94; $P=.004$ ).

Finally, no differences were found in operative findings, preoperative or postoperative medications, delay from MI, survival, rate of hospitalization for heart failure, cardiac events, and cardiac procedures. Overall, the number of events was low: 2 patients died at 8 and 30 months after the operation in group 1 and 6 patients died in group 2. Eight patients were hospitalized for cardiac cause during the follow-up interval (6 for heart failure, 2 for arrhythmias) in group 1 and 20 patients in group 2 ( 8 for congestive heart failure, 7 for arrhythmias, 1 for acute MI, 2 for unstable angina, and 2 for stroke). Cardiac procedures included 4 percutaneous transluminal angioplasties in group 2, 4 cardioverter-defibrillator implantations in group 1, and 7 in group 2. Overall, $93 \%$ of group 1 patients and $87 \%$ of group 2 were free from major cardiac and cardiovascular events (any-cause death, acute MI, stroke, and revascularization).

Figure 3 shows Kaplan-Meier survival curve in the 2 groups for all-cause mortality. Average followp-up (100\% complete) was $43 \pm 22$ months.
TABLE 2. Preoperative and early postoperative factors in patients with (group 1) and without (group 2) late diastolic restriction

\begin{tabular}{|c|c|c|c|}
\hline & $\begin{array}{l}\text { Group 1 } \\
(\mathbf{n}=\mathbf{2 8})\end{array}$ & $\begin{array}{c}\text { Group 2 } \\
(\mathrm{n}=101)\end{array}$ & $P$ value \\
\hline Age (y) & $62 \pm 8$ & $66 \pm 9$ & .036 \\
\hline \multicolumn{4}{|l|}{ Preoperative } \\
\hline $\mathrm{DD}(\mathrm{mm})$ & $66 \pm 8$ & $62 \pm 8$ & .050 \\
\hline $\mathrm{SD}(\mathrm{mm})$ & $54 \pm 10$ & $49 \pm 10$ & .024 \\
\hline $\operatorname{EDVI}\left(\mathrm{mL} / \mathrm{m}^{2}\right)$ & $123 \pm 30$ & $109 \pm 44$ & .106 \\
\hline $\operatorname{ESVI}\left(\mathrm{mL} / \mathrm{m}^{2}\right)$ & $89 \pm 30$ & $73 \pm 40$ & .07 \\
\hline $\mathrm{EF}(\%)$ & $29 \pm 8$ & $35 \pm 9$ & .018 \\
\hline PAP systolic $(\mathrm{mm} \mathrm{Hg})$ & $36 \pm 10$ & $34 \pm 9$ & .437 \\
\hline Left atrium $(\mathrm{mL})$ & $47 \pm 6$ & $43 \pm 7$ & .006 \\
\hline Short axis (systole) $(\mathrm{mm})$ & $48 \pm 9$ & $40 \pm 9$ & .002 \\
\hline SI diastolic & $0.57 \pm 0.8$ & $0.51 \pm 0.9$ & .024 \\
\hline SI systolic & $0.51 \pm 0.10$ & $0.42 \pm 0.12$ & .019 \\
\hline CI systole & $0.89 \pm 0.19$ & $1.02 \pm 0.25$ & .050 \\
\hline Diastolic pattern & $1.72 \pm 0.6$ & $1.26 \pm 0.7$ & .003 \\
\hline \multicolumn{4}{|l|}{ Early postoperative } \\
\hline $\mathrm{DD}(\mathrm{mm})$ & $65 \pm 7$ & $58 \pm 8$ & .000 \\
\hline $\mathrm{SD}(\mathrm{mm})$ & $54 \pm 9$ & $46 \pm 8$ & .001 \\
\hline $\operatorname{EDVI}\left(\mathrm{mL} / \mathrm{m}^{2}\right)$ & $86 \pm 26$ & $70 \pm 18$ & .000 \\
\hline $\operatorname{ESVI}\left(\mathrm{mL} / \mathrm{m}^{2}\right)$ & $56 \pm 20$ & $42 \pm 14$ & .000 \\
\hline $\mathrm{EF}(\%)$ & $35 \pm 9$ & $41 \pm 9$ & .015 \\
\hline PAP systolic $(\mathrm{mm} \mathrm{Hg})$ & $35 \pm 10$ & $30 \pm 8$ & .201 \\
\hline Left atrium $(\mathrm{mL})$ & $47 \pm 7$ & $41 \pm 7$ & .001 \\
\hline Short axis (mm) (systole) & $48 \pm 7$ & $38 \pm 8$ & .002 \\
\hline SI diastolic & $0.67 \pm 0.12$ & $0.51 \pm 0.9$ & .001 \\
\hline SI systolic & $0.62 \pm 0.14$ & $0.48 \pm 0.1$ & .000 \\
\hline CI systole & $0.70 \pm 0.11$ & $0.75 \pm 0.11$ & .758 \\
\hline Diastolic pattern & $2.0 \pm 0.68$ & $1.34 \pm 0.65$ & .001 \\
\hline
\end{tabular}

$D D$, Diastolic internal diameter; $S D$, systolic internal diameter; $E D V I$, end-diastolic volume index; $E S V I$, end-systolic volume index; $E F$, ejection fraction; $P A P$, pulmonary artery pressure; $S I$, sphericity index; $C I$, conicity index.

Table 3 shows cardiac function changes at the 3 time intervals in patients with (group 1) and without restriction (group 2). Patients with restriction had a nonsignificant reduction of internal diameters, and LV volumes remained greater than in patients without restriction. However, cardiac function and clinical status improved significantly in both groups.

\section{DISCUSSION}

The major findings of this study include the following: (1) Baseline diastolic dysfunction occurs in most patients affected by ischemic dilated cardiomyopathy referred for SVR. The most frequent dysfunction is an abnormal relaxation pattern $(65 \%)$ followed by pseudonormalization $(26 \%)$ and by restrictive pattern (5\%). (2) Patients in whom diastolic restriction develops late postoperatively had preoperatively larger, more spherical ventricles with a lower ejection fraction and more conical apex. LV shape was of nonaneurysmal type. Patients with preoperative mild diastolic dysfunction (pseudonormalized pattern) and with increased short axis (increased septolateral dimensions) 


\section{Kaplan Meyer Survival Curve according to late diastolic filling pattern}
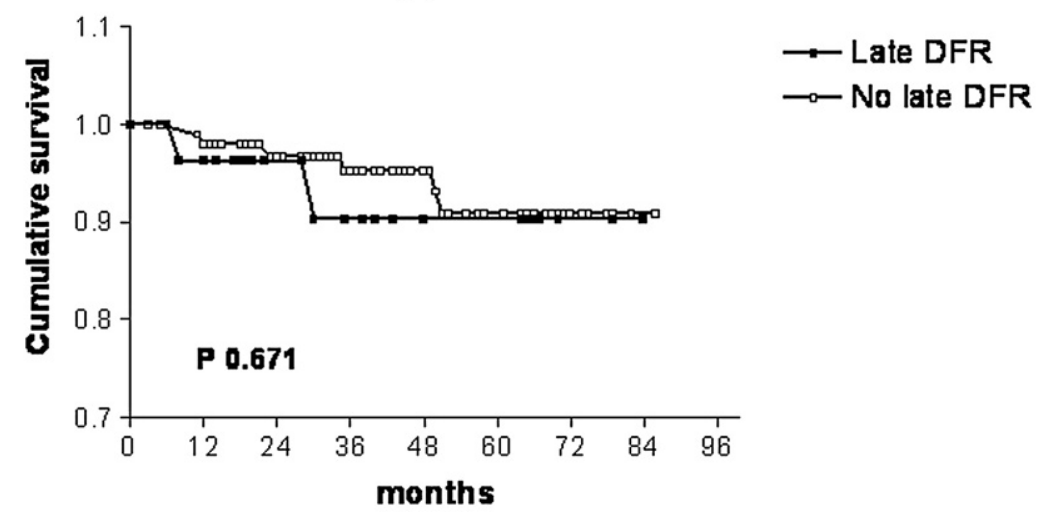

\begin{tabular}{|c|c|c|c|c|c|c|c|}
\hline & Baseline & 12 & 24 & 36 & 48 & 60 & 72 \\
\hline Group 1 & 28 & 26 & 18 & 15 & 11 & 10 & 4 \\
\hline Group 2 & 101 & 96 & 80 & 66 & 56 & 30 & 8 \\
\hline
\end{tabular}

FIGURE 3. Kaplan-Meier survival function (all-cause mortality) according to the postoperative diastolic pattern at follow-up. $D F R$, Diastolic filling restriction.

were more likely to have diastolic restriction after SVR; (3) Worsening in diastolic function, as evaluated by transmitral flow velocity curves, does not affect postoperative morbidity or mortality.

\section{SVR and Diastolic Function}

During diastole, the left ventricle should be able to accept a wide range of blood volumes without an elevation in filling pressure. The healthy ventricle also completes most of its filling during the initial phases of diastole; this property is particularly helpful at rapid heart rates when diastole is shortened.

Almost any process that affects the systolic function of the myocardium or increases its mass or connective tissue content affects diastolic function as well. Impaired LV relaxation and/or poor LV compliance may lead to elevated filling pressures, pulmonary congestion, and clinical symptoms of heart failure.

Normally, early flow (E wave) is higher than that associated with atrial contraction (A wave). Early diastolic dysfunction is typically associated with a reversal of the E/A ratio. However, as diastolic compliance worsens and $\mathrm{LV}$ end-diastolic pressure increases, the E/A ratio becomes " "pseudonormalized.' End-stage or restrictive diastolic dysfunction is associated with an $\mathrm{E} / \mathrm{A}$ ratio greater than 2 and/or with a transmitral flow velocity pattern of type 3 or $4 .{ }^{13} \mathrm{LV}$ diastolic dysfunction is a constant finding in patients after acute MI, reflecting LV overload and increased filling pressure, and our patients confirm that baseline diastolic dysfunction is present in almost all patients.

The effects of SVR on ventricular function and the related effects of diastolic dysfunction on outcome after SVR have not been well studied. ${ }^{8}$ The study by Tulner and colleagues ${ }^{11}$ was the first in which the diastolic pressure/volume

TABLE 3. Cardiac function changes at the 3 time intervals

\begin{tabular}{|c|c|c|c|c|}
\hline Variable & Preop & Discharge & Follow-up & $P$ value \\
\hline \multicolumn{5}{|l|}{ Group $1(n=28)$} \\
\hline $\mathrm{DD}(\mathrm{mm})$ & $66 \pm 8$ & $65 \pm 7$ & $66 \pm 8$ & .499 \\
\hline $\mathrm{SD}(\mathrm{mm})$ & $54 \pm 10$ & $54 \pm 9$ & $54 \pm 10$ & .733 \\
\hline $\operatorname{EDVI}\left(\mathrm{mL} / \mathrm{m}^{2}\right)$ & $123 \pm 30$ & $86 \pm 26$ & $108 \pm 36$ & .011 \\
\hline $\operatorname{ESVI}\left(\mathrm{mL} / \mathrm{m}^{2}\right)$ & $89 \pm 30$ & $56 \pm 20$ & $69 \pm 31$ & .011 \\
\hline $\mathrm{EF}(\%)$ & $29 \pm 8$ & $36 \pm 6$ & $36 \pm 9$ & .047 \\
\hline NYHA & $2.4 \pm 0.7$ & $\mathrm{n} / \mathrm{a}$ & $1.7 \pm 0.6$ & .0018 \\
\hline Diastolic pattern & $1.72 \pm 0.7$ & $2.0 \pm 0.7$ & $3.3 \pm 0.5$ & .0001 \\
\hline Deceleration time (ms) & $183 \pm 54$ & $167 \pm 36$ & $131 \pm 28$ & .0002 \\
\hline \multicolumn{5}{|l|}{ Group $2(n=101)$} \\
\hline $\mathrm{DD}(\mathrm{mm})$ & $62 \pm 8$ & $58 \pm 8$ & $58 \pm 7$ & .0005 \\
\hline $\mathrm{SD}(\mathrm{mm})$ & $49 \pm 10$ & $46 \pm 8$ & $45 \pm 9$ & .009 \\
\hline $\operatorname{EDVI}\left(\mathrm{mL} / \mathrm{m}^{2}\right)$ & $109 \pm 44$ & $70 \pm 18$ & $83 \pm 23$ & .0001 \\
\hline $\operatorname{ESVI}\left(\mathrm{mL} / \mathrm{m}^{2}\right)$ & $73 \pm 40$ & $42 \pm 14$ & $47 \pm 20$ & .0001 \\
\hline $\mathrm{EF}(\%)$ & $34 \pm 9$ & $41 \pm 10$ & $42 \pm 9$ & .0001 \\
\hline NYHA & $2.5 \pm 0.8$ & N/A & $1.5 \pm 0.6$ & .0001 \\
\hline Diastolic pattern & $1.26 \pm 0.7$ & $1.34 \pm 0.6$ & $1.22 \pm 0.6$ & .4956 \\
\hline Deceleration time (ms) & $213 \pm 57$ & $178 \pm 52 *$ & $212 \pm 50$ & $.0001 *$ \\
\hline
\end{tabular}

$D D$, Internal diastolic diameter; $S D$, internal systolic diameter; $E D V I$, end-diastolic volume index; $E S V I$, end-systolic volume index; $E F$, ejection fraction; $N Y H A$, New York Heart Association; N/A, not assessed. *Versus baseline. 
relationship was measured in patients before and early after SVR. In that study, diastolic compliance appears to be reduced early after SVR, leading to a reduction in stroke volume. In a previous article, $\mathrm{we}^{16}$ reported changes in diastolic function after SVR, in a series of 30 patients evaluated by pressure/volume loops, and found significant improvement early after surgery in filling pressure and in parameters of diastolic function (peak filling rate, time to peak filling rate, and Tau), as well as in the diastolic pressure/volume curves; however, at 1 year there was a return to baseline of all diastolic parameters except peak filling rate, which remained improved.

The factors most likely to affect diastolic function are the size and the quality of myocardium of the residual LV cavity. Excessive volume reduction probably causes diastolic compliance to shift further to the left on the pressure/volume curve, thereby producing diastolic heart failure. This may have been the genesis of the unsatisfactory results obtained with standard linear aneurysm repair. ${ }^{17}$

With the introduction of sizing devices helping LV reconstruction, the risk of leaving a residual cavity that is too small is almost absent, but at the present time there is no objective evidence to support the selection of a particular postoperative size. In the present study, patients in whom restriction developed had a postoperative end-diastolic and end-systolic volume higher than patients in whom restriction did not develop, as shown in Table 2; they had larger LV volume also preoperatively (although not significantly so) and worse geometric parameters (greater internal dimensions, larger atrial size) (Table 2). The preoperative LV shape was more spherical and nonaneurysmal (without the classic neck and without demarcation of the transitional zone) in patients with late restriction. The amount of LV reduction was not significantly different in the 2 groups. None of the patients with classic aneurysm had diastolic restriction at follow-up. In a recent article, we $\mathrm{e}^{15}$ demonstrated that preoperative LV shape is a significant predictor of early diastolic dysfunction after SVR (evaluated as an increase of at least 1 class of diastolic filling pattern at discharge); the present study confirms that nonaneurysmal LV shape is more likely associated with diastolic restriction at follow-up.

\section{Diastolic Dysfunction and Clinical Status}

Our group demonstrated that end-stage or restrictive diastolic dysfunction (E/A ratio $>2$ ) increased early mortality in 254 patients undergoing SVR when associated with advanced New York Heart Association functional class and with MR greater than $2+.{ }^{5}$ In the present study, we found that the worsening in diastolic function induced by SVR did not affect clinical status and survival. Survival curve is excellent both in patients with and in those without postoperative diastolic dysfunction; there are no differences in cardiac events/procedures, rate of cardiac hospitalization, in our 2 groups of patients. Clinical status, as evaluated by New
York Heart Association classification, and systolic function significantly improve in both groups. The issue that diastolic dysfunction has little impact on clinical course is problematic and needs some comments. A possible explanation is that the significant improvement in systolic function and the optimal medical treatment, which is not discontinued after surgery, counteracts diastolic dysfunction. An interesting finding is that patients with late diastolic dysfunction appear to have a secondary dilatation within the first year (increase in LV size from discharge to follow-up), whereas in the other group LV dimensions remained fairly stable (Table 3). A secondary dilatation was also observed by Qin, ${ }^{18}$ Bovè, ${ }^{19}$ and their coworkers after SVR and was found to be promoted by recurrent MR. We observed an analogous correlation between the presence of diastolic restriction, significant late MR, and redilatation of the ventricle. It is therefore possible that the presence of MR leads to a misinterpretation of severe diastolic dysfunction when evaluated by transmitral flow velocity pattern.

\section{Limitations of the Study}

The major limitation of the present study is the use of 2-dimensional echocardiography. This technique has known limitations concerning the accuracy of volume measurements in geometrically deformed left ventricles. This limitation is, however, minimized by the repeated use of the same method by the same person. Moreover, diastolic function was analyzed noninvasively with transmitral flow velocity pattern, which can vary within 1 patient during a day, depending on exercise, treatment options, and loading conditions (as for the presence of MR). Therefore, tissue Doppler velocity curves that are load independent and more sensitive than conventional transmitral flow indices and/or 3-dimensional echocardiography in experienced hands are undeniably better tools to refine these measurements. ${ }^{19,20}$

Finally, the study is retrospective, nonrandomized, and not powered for mortality; therefore, inasmuch as the sample size is small, the events are few, and a control group having coronary artery bypass without SVR is lacking, we cannot drive conclusions on the clinical impact of diastolic dysfunction on outcome after SVR. The recently released STICH trial results (Surgical Trial in IntraCerebral Haemorrhage) showed that SVR does not add benefit in respect to coronary artery bypass alone, but the article does not report data either preoperatively or postoperatively on diastolic function. ${ }^{21}$

\section{CONCLUSIONS}

The diastolic restrictive pattern observed after SVR in nearly $20 \%$ of patients correlates preoperatively with more severe hemodynamic and geometric abnormalities and postoperatively with the presence of significant MR at followup. The latter finding may explain the low impact of "severe diastolic dysfunction" on clinical outcome. Survival is good and major cardiac events are few in this ischemic population 
treated with SVR, independent on whether diastolic dysfunction develops.

\section{References}

1. Dor V, Saab M, Coste P, Kornaszewska M, Montiglio F. Left ventricular aneurysm: a new surgical approach. Thorac Cardiovasc Surg. 1989;37:11-9.

2. Athanasuleas CL, Buckberg GD, Stanley AWH, Siler W, Dor V, Di Donato M, et al. Surgical ventricular restoration in the treatment of congestive heart failure due to post-infarction ventricular dilation. J Am Coll Cardiol. 2004;44: 1439-45.

3. Di Donato M, Sabatier M, Dor V, Toso A, Maioli M, Fantini F. Akinetic versus dyskinetic postinfarction scar: relation to surgical outcome in patients undergoing endoventricular circular patch plasty repair. J Am Coll Cardiol. 1997;29:1569-75.

4. Menicanti L, Di Donato M. The Dor procedure: what has changed after fifteen years of clinical practice? J Thorac Cardiovasc Surg. 2002;124:886-90.

5. Menicanti L, Castelvecchio S, Ranucci M, Frigiola A, Santambrogio C, De Vincentiis C, et al. Surgical therapy for ischemic heart failure: single-center experience with surgical anterior ventricular restoration. J Thorac Cardiovasc Surg. 2007; 134:433-41

6. Maxey T, Reece T, Ellman P, Butler PD, Kern JA, Tribble GC, et al. Coronary artery bypass with ventricular restoration is superior to coronary artery bypass alone in patients with ischemic cardiomyopathy. $J$ Thorac Cardiovasc Surg. 2004; 127:428-34

7. Mickleborough L, Merchant N, Ivanov R, Vivek J, Carson S. Left ventricular reconstruction: early and late results. J Thorac Cardiovasc Surg. 2004;128:27-37.

8. Burkhoff D, Wechsler AS. Surgical ventricular remodeling. A balancing act on systolic and diastolic properties. J Thorac Cardiovasc Surg. 2006;132:459-63.

9. Dickstein ML, Spotnitz HM, Rose EA, Burkhoff D. Heart reduction surgery: an analysis of the impact on cardiac function. J Thorac Cardiovasc Surg. 1997;113: 1032-40.

10. Ratcliffe MB, Wallace AW, Salahieh A, Hong J, Ruch S, Hall TS. Ventricular volume, chamber stiffness, and function after anteroapical aneurysm plication in the sheep. J Thorac Cardiovasc Surg. 2000;119:115-24.

11. Tulner SAF, Steendijk P, Klautz RJM, Bax JJ, Schalij MJ, Van Der Wall EE, et al. Surgical ventricular restoration in patients with ischemic dilated cardiomyopathy: evaluation of systolic and diastolic ventricular function, wall stress, dyssyn- chrony, and mechanical efficiency by pressure-volume loops. $J$ Thorac Cardiovasc Surg. 2006;132:610-20.

12. Di Donato M, Castelvecchio S, Kukulski T, Bussadori C, Giacomazzi F, Frigiola A, et al. Surgical ventricular restoration: left ventricular shape influence on cardiac function, clinical status, and survival. Ann Thorac Surg. 2009;87: 455-61.

13. Nishimura R, Tajik A. Evaluation of diastolic filling of left ventricle in health and disease: Doppler echocardiography is the clinician's Rosetta Stone. J Am Coll Cardiol. 1997;30:8-18.

14. Dor V, Di Donato M, Sabatier M, Montiglio F, Civaia F. Left ventricular reconstruction by endoventricular circular patch plasty repair: a 17-years experience. Semin Thorac Cardiovasc Surg. 2001;13:435-47.

15. Castelvecchio S, Menicanti L, Ranucci M, Di Donato M. Impact of surgical ventricular restoration on diastolic function: implications of shape and residual ventricular size. Ann Thorac Surg. 2008;86:1849-54

16. Di Donato M, Toso A, Dor V, Sabatier M, Barletta G, Menicanti L, et al. Surgica ventricular restoration improves mechanical intraventricular dyssynchrony in ischemic cardiomyopathy. Circulation. 2004;109:2536-43.

17. Ratcliffe MB, Guy TS. The effect of preoperative diastolic dysfunction on outcome after surgical ventricular remodeling. J Thorac Cardiovasc Surg. 2007; 134:280-3.

18. Qin JX, Shiota T, McCarthy PM, Asher CR, Hail M, Agler DA, et al. Importance of mitral valve repair associated with left ventricular reconstruction for patient with ischemic cardiomyopathy: a real time three dimensional echocardiographic study. Circulation. 2003;108(Suppl II):241-6.

19. Bovè T, Belleghem YV, Vandeplas G, Caes F, Francois K, De Backer J, et al Short-term systolic and diastolic ventricular performance after surgical ventricular restoration for dilated ischemic cardiomyopathy. Eur J Cardiothorac Surg. 2009; 35:995-1003.

20. Dolzhenko MN, Rudenko SA, Potashev SV, Simagina TV, Nosenko NN Kravchenko TG. Left ventricle diastolic function in the patients after coronary arteries bypass graft combined with left ventricle aneurismectomy according to tissue Doppler imaging: one year follow-up. Postgrad Med J. 2007;83: 320-4.

21. Jones RH, Velazquez EJ, Michler RE, Sopko G, Oh JK, O'Connor CM, et al., for the STICH Hypothesis 2 Investigators. Coronary bypass surgery with or without surgical ventricular reconstruction. N Engl J Med. 2009;360:1705-17. 


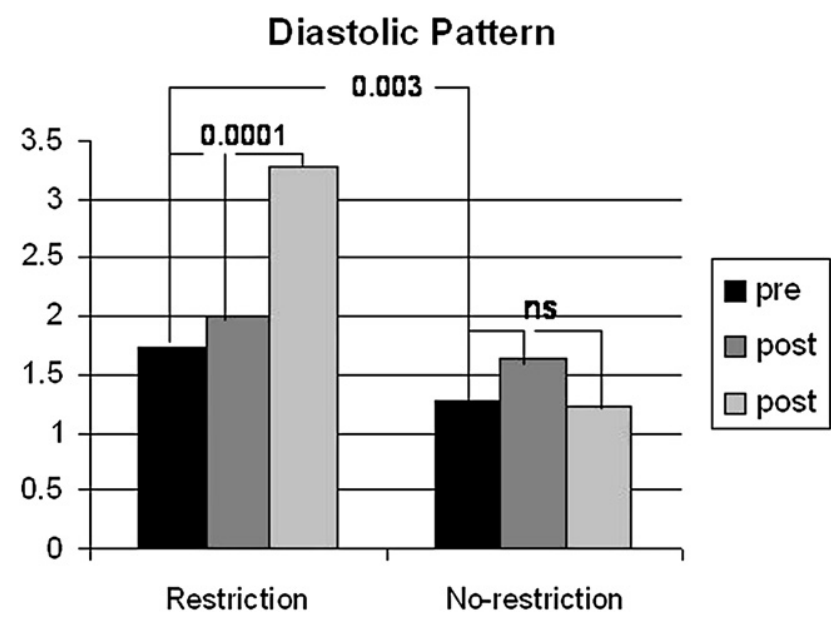

FIGURE E1. Diastolic pattern at the 3 time intervals in patients with and without diastolic restriction at follow-up. NS, Not significant. 